\title{
Entre la democracia y lo democrático: crítica de la razón formal*
}

\section{Between Democracy and the Democratic: Critique of Formal Reason}

\section{Sebastián Ronderos**}

Recibido: 7 de agosto de 2014

Aprobado: 1 de junio de 2016

Disponible en línea: 30 de enero de 2017

\section{Resumen}

Este artículo se orienta hacia la problematización de conceptos esenciales en la teoría crítica, en su preocupación por reconfigurar los procesos de deliberación en el ámbito público-político, la institucionalización de las voluntades propias de este espacio y generar un diálogo entre perspectivas posibles en la transformación de las estructuras políticas. Se analizan los conceptos fundamentales en la teoría de Jürgen Habermas, tanto en la reconstrucción del materialismo histórico como en la consolidación de la teoría de la acción comunicativa, y así reedificar su comprensión de lo político. Se discute el papel de la neutralidad y el consenso en esta comprensión, cuestionando a su vez la predominancia de marcos formales en la reconfiguración de "la

\section{Abstract}

The present work is oriented towards the problematization of essential concepts in critical theory, in a concern about reconfiguring the processes of deliberation in the public-political sphere, the institutionalization of the wills that emerge from that space, and to generate a dialogue between possible perspectives in the transformation of political structures. The fundamental concepts in Jürgen Habermas' theory are analyzed in both the reconstruction of Historical Materialism and the consolidation of the Theory of Communicative Action, thus rebuilding his understanding of the political. The role of neutrality and consensus in this understanding is debated, in turn questioning the predominance of formal frameworks in

doi:10.11144/Javeriana.papo22-1.eddc

\footnotetext{
* Artículo de revisión

** Politólogo por la Universidad de los Andes, con énfasis en Teoría Política y estudios complementarios en Filosofía, especialista en Resolución de Conflictos por la Pontificia Universidad Javeriana, especialista en Globalización y Cultura por la Fundação Escola de Sociologia e Política de São Paulo, magíster en Cultura de Paz, Conflicto, Educación y Derechos Humanos por la Universidad de Granada, España, y doctorando en Política Comparada en el Instituto de Ciências Sociais da Universidade de Lisboa. Correo electrónico: se.ronderos52@uniandes.edu. co Orcid: http://orcid.org/0000-0003-4254-6207
} 
democracia”. Finalmente, trasladamos el ejercicio democrático por fuera de los andamiajes institucionales, proveyéndolo de un carácter crítico, dialéctico y comunitario, que no niega la conflictividad ni en los actos comunicativos ni en los procesos normativos.

\section{Palabras clave:}

teoría de la acción comunicativa; evolución social; teoría de sistemas; crisis; democracia deliberativa; hermenéutica; teoría crítica the reconfiguration of "Democracy". Finally, we transfer the democratic exercise outside a determined institutional scaffolding, providing it with a critical, dialectical and community characters, which don't deny conflictivity neither in communicative acts nor in normative processes.

\section{Keywords:}

theory of communicative action; social evolution; systems theory; crisis; deliberative democracy; hermeneutics; critical theory

\section{Cómo citar este artículo:}

Ronderos, S. (2017). Entre la democracia y lo democrático: crítica de la razón formal. Papel Político, 22(1), 9-33. https://doi.org/10.11144/ Javeriana.papo22-1.eddc 


\section{Introducción}

La discusión sobre la democracia, la representación y las formas de organización socialcolectiva ha tomado una destacada relevancia en las ciencias sociales, fruto de una aparente fragmentación en la legitimidad de las estructuras de poder, hoy expresas en las modernas nociones de Estado nación y democracia representativa.

Las concepciones contemporáneas de poder están impregnadas, como describen Negri y Hardt (2009), de una especie de apopcaliptismo ante la avenencia de nuevos imperialismos y nuevos fascismos que se fortalecen, en un panorama global donde la segregación y la violencia se consolidan como primer recurso. Se observa una relocalización de los espacios de toma de decisión (Habermas, 1998); una deslegitimación de los procesos de representación ante crecientes abstencionismos electorales y movilizaciones sociales heterogéneas (como en junio de 2013 en Brasil, pasando por la Primavera Árabe, el 15-M en España, el Diren Gezi en Turquía, YoSoy132 o el Occupy Wall Street); una creciente desigualdad y desregulación de la economía, relativa a los circuitos y flujos de la globalización financiera y del capital internacional (Negri y Hardt, 2000, 2009); una aparente emergencia en la composición de los movimientos sociales, al tomar distancia gradualmente de las nociones tradicionales de trabajo operario, revitalizando identidades de subalternidad, antes latentes, naturalizadas o reprimidas por el significante central de trabajo asalariado, pero que entran a tomar protagonismo en la composición organizacional de los movimientos sociales, ya no solo conformados por trabajadores, sino por campesinos, indígenas, mujeres, homosexuales, defensores de derechos humanos, negros, etc. (De Sousa Santos, 2016).

Este contexto ha llevado a diversos teóricos a reflexionar sobre nuevas formas de dominación y violencia, aunque menos perceptibles y mediatizadas que las guerras interestatales previas a la implosión del bloque soviético. Resultan más complejas, mortales y sistémicamente articuladas, encarnadas en la propiedad y el capital, totalmente amparadas por los marcos legales.

La noción de dominación desde la propiedad y el capital, fundamentada a través de procesos legales y constitucionales, describe propiamente lo que el sociólogo y matemático noruego Johan Galtung (1996), padre de los estudios de la paz y los conflictos, caracterizó como violencia estructural. La violencia estructural se expresa como una forma de violencia indirecta, causa de una injusticia sistémica que genera exclusión, segregación y desigualdad social. La muerte de un niño por diarrea - para dar un ejemplo- expresa una violencia descarnada, pero invisible, pues resulta problemático identificar a su agresor con nombre y apellido. Es fruto de la cruda expresión de un sistema perverso que reproduce escasez por la acumulación de riqueza y provoca violencia por exclusión. Lo que Žižek (2014) describirá como violencia objetiva, 
más extrañamente inquietante que cualquier forma directa de violencia social e ideológica pre-capitalista: esta violencia ya no puede ser atribuida a individuos concretos y sus "malas" intenciones, pero es puramente “objetiva”, sistémica, anónima. (p. 20)

La constitución del poder se basa en las formas de violencia estructural que encuentran un terreno de legitimidad desde la noción de que vivimos en sistemas democráticos, donde el contenido de este concepto, demos kratos, acaba por reducirse a la participación ciudadana esporádica y marginal, a través de las urnas y la libre competencia de partidos políticos.

Derivado de los límites y las lagunas que devienen los marcos formalistas, tanto en la teoría de la elección racional como en la teoría del derecho y de Estado democrático frente a cómo entender, críticamente, el fundamento ético en los procesos normativos, este artículo busca, con el mayor grado de reflexividad posible, generar una problematización conceptual proveniente de la teoría crítica (Habermas en especial), desarrollar una descripción analítica de la teoría discursiva del derecho, someter a validación ciertas categorías en su reconstrucción de los procesos de configuración normativa y plantear, modestamente, unas bases críticas que permitan repensar el fundamento del espíritu de lo democrático. Busca un diálogo teórico que permita, en primera instancia, explorar las bases para una posible reconfiguración de las estructuras políticas, desde la teoría de la acción comunicativa y su discusión referente a la teoría de sistemas y, finalmente, problematizar y evidenciar nuevos marcos interpretativos en la relación entre Estado, participación ciudadana y acción política.

Convenimos con la reconstrucción epistemológica que desarrolla Habermas, reconociendo la importante y permanente dinámica de transformación social que se genera en el mundo de la vida como causa de la complejidad social y en relación con la razón sistémica. Sin embargo, reconociendo además sus vacíos al olvidar, o dar un papel secundario, a las relaciones de dominación que se dan en el mundo de la vida y que atravesarían también los procesos en la toma de decisión durante la deliberación, generando una teoría formalista, alejada de la función crítica.

Se argumenta, y como hipótesis central, que el diálogo en condiciones de igualdad es utópico, imperfecto e imposible en su totalidad, limitado siempre por el inmovilismo de las instituciones (razón sistémica) en relación con el dinamismo con que se transforman constantemente las sociedades (mundo de la vida), teniendo, pues, que recurrir, constantemente, a una concepción positiva del poder político, transfiriendo "lo democrático" por fuera de los andamiajes institucionales y, por tanto, estableciendo una crítica frente a los marcos normativistas y formales en la teoría democrática.

\section{La doble dimensión de la teoría social}

Se ha realizado un importante aporte en la apertura de una teoría social, basada en una doble dimensión como fundamento de la acción social, que ha roto con una tradición 
predominante que pretende dar cuenta de la acción del sujeto desde lógicas unidimensionales, bien desde una perspectiva sistémica, bien desde un plano meramente subjetivo (Habermas, 1981a; Luhmann, 1995; Parsons, 1951).

Durkheim, por ejemplo, en La división del trabajo social, reconoció las dos dimensiones en solidaridad mecánica y solidaridad orgánica, sin embargo, llenando de ambigüedad esta doble dimensión al adjudicar la solidaridad mecánica a las sociedades poco segmentadas, relegando solo el ámbito sistémico en la solidaridad orgánica a las sociedades con una fuerte segmentación y una compleja división social del trabajo social. En ese sentido, olvida la interacción intersubjetiva en la sociedad moderna, donde reconoce solo el ámbito sistémico y, concediendo la cohesión intersubjetiva a la sociedad primitiva, negando, finalmente, el carácter moral en la sociedad moderna.

Este enfoque, si bien reconoce el ámbito sistémico, resalta, además, su carácter intersubjetivo, basándose en buena medida en la teoría social desarrollada por Talcott Parsons, considerada como una de las teorías sociales de mayor complejidad entre los contemporáneos (Habermas, 1981b, p. 281).

La teoría parsoniana estuvo relegada a un segundo plano en buena parte de la década de 1960, por una predominancia de lecturas dogmáticas y heterogéneas del marxismo, vinculadas a la ideología estalinista. Dicha teoría presume una comprensión sistémica y cibernética de la sociedad, pues supone un orden jerárquico de los sistemas en referencia al control de la acción. Parsons parte de una teoría normativa de la acción a una formulación de la teoría sistémica de la sociedad, que si bien el filósofo alemán, Jürgen Habermas, la reconoce como la más compleja, busca evidenciar sus limitaciones para constituir un concepto suficiente de sociedad, por medio de la teoría de la evolución social y, posteriormente, la teoría de la acción comunicativa, las cuales desarrollaré más adelante.

Habermas (1981b) centra esta discusión en demostrar la insuficiencia de las teorías que se han desarrollado hasta entonces de la sociedad. El argumento repetido, en todos sus diálogos con la teoría social, se basa en que la teoría debe dar cuenta de las dos dimensiones sociales, la sistémica (objetiva) y el mundo de la vida (subjetiva). La relación entre teoría de la acción y la teoría sistémica de la sociedad depende de una articulación metodológica, entre un esquema objetivante y un esquema conceptual, que busque una reconstrucción de la intersubjetividad, entendiendo, como lo comprendía Marx, que el sujeto lleva siempre consigo a la comunidad. Sin embargo, Parsons deja de lado la comprensión hermenéutica, por tanto, pierde el esencial interés metodológico de vincular las dos dimensiones (Habermas, 1981b, p. 289).

En su primera gran obra, La estructura de la acción social (1937), Parsons desarrolla un modelo voluntarista donde los actores poseen habilidades cognitivas y donde hay una fijación de un fin al tomar decisiones orientadas normativamente. Bajo este modelo, la teoría de la acción queda relegada a un ámbito exclusivamente subjetivo. Se plantea, 
entonces, la acción como una sucesión de fines por un esfuerzo personal que se ve recompensado por un logro. Por otra parte, la acción se ve enmarcada bajo una observancia de estándares normativos, determinada, pues, por normas y valores. Aquí las normas no se realizan por ellas mismas, sino solo mediante la acción del sujeto.

En esta primera etapa de la teoría de la acción, en su esfuerzo voluntarista, Parsons comprende la acción desde un ente solitario y abstraído. Por tanto, y al tener en cuenta solo esta dimensión, no logra dar cuenta de la orientación normativa de la acción. "Más qué significa que un actor oriente sus decisiones por valores es algo que Parsons no puede explicar mientras limite su análisis a la unidad elemental de la acción" (Habermas, 1981b, p. 292).

En una siguiente etapa de la construcción teórica de la acción, Parsons busca explicar una correspondencia entre institucionalización e internalización de los valores, estableciendo un doble carácter del concepto de libertad (personal y suprapersonal), y a su vez dos modos de coordinación de la acción: 1) complementariedad de tramos de intereses y 2) consenso valorativo. En el primer caso, se establece un orden fáctico de secuencias de acciones reguladas empíricamente; y en el segundo, surge fruto de un orden institucional que regula las relaciones interpersonales de forma legítima. ${ }^{1}$ Parsons, no obstante, expresa su convicción en que los órdenes sociales no pueden establecerse mediante intereses, dejando de lado su carácter normativo. Aisló los conceptos de acción y orden, por lo que se vio forzado a reformular su planteamiento teórico de la acción.

Hasta entonces, su teoría se había limitado a descomponer la acción bajo el lente de una realización de fines orientada por valores. Sin embargo, a partir de la década de 1950, se embarca en el análisis conceptual entre motivaciones y orientaciones valorativas y consolida una segunda versión de su teoría de la acción.

En esta segunda versión, Parsons ya no relega los estándares valorativos a actores individuales, sino que introduce los patrones culturales como posesión intersubjetiva. En esta relación, la cultura se involucra con la orientación de la acción solo por medio de componentes evaluativos, lo cual Habermas llamaría estándares culturales de valor. Se reconoce correctamente el valor del lenguaje como el medio por excelencia para que se lleve a cabo la transmisión de la cultura:

Los prerrequisitos culturales mínimos de un sistema social, se puede decir, por ello, que operan, al menos en parte, a través de las funciones de la cultura para la personalidad. Sin los recursos culturales requeridos que tienen que ser asimilados a través de la internalización, no es posible que surja un nivel humano de personalidad y, en consecuencia, que se

\footnotetext{
${ }^{1}$ Estos planteamientos son formulados bajo el concepto de autoridad moral de Emilio Durkheim y el concepto
} de legitimidad de Max Weber. 
desarrolle un tipo humano de sistema social. El otro aspecto del problema de los prerrequisitos culturales lo constituyen los recursos y organizaciones culturales adecuados para el mantenimiento del sistema social. Sobre esto ya hemos dicho algo anteriormente, pero se pueden añadir algunas notas. El conocimiento instrumental quizá sea el tipo más obvio de ejemplo. Sin un mínimo de saber técnico que haga posible tratar con el medio físico y con otros seres humanos no sería posible una sociedad humana. Esto, a su vez, presupone el lenguaje. (Parsons, 1951, p. 25)

La acción en el marco de una cultura significa una interacción de los sujetos que dan una interpretación en cuanto al saber construido intersubjetivamente. Esto refleja un entendimiento de la apropiación interpretativa de los contenidos culturales que determinan la acción cultural. Pero Parsons, en vez de entender la orientación por valores, como queda planteado, entiende la orientación solo por objetos. En esta orientación objetual, hace una categorización de objetos físicos y objetos culturales ontológicamente, pero no es tomada en cuenta la dimensión comunicacional, que, al final, es la única dimensión que puede dar cuenta o generar acceso a los significados materializados simbólicamente.

Parsons desconoce esta diferencia y asimila los patrones culturales susceptibles de tradición de elementos de la situación a los que el actor se refiere como si se tratara de objetos. Esta reificación no le permite percatarse del papel que juega la tradición cultural como contexto y trasfondo de la acción comunicativa (las cursivas son mías). (Habermas, 1981b, p. 312)

El trato que da Parsons a la cultura, en cuanto a la idea de que es internalizada e institucionalizada en componentes empíricos del objeto, la sustrae completamente de cualquier tipo de interacción subjetiva. Sostiene que la sociedad tiene tres componentes de la acción: 1) cultura, 2) sociedad y 3) personalidad (Parsons, 1951, p. 6), pero no parece preocuparse por el papel del entendimiento en la interacción de estas partes.

Lo más adecuado sería basarse en una estructura de la acción orientada al entendimiento, para así dar cuenta de la cultura, la sociedad y la personalidad en las orientaciones que determinan la acción. Solo a través de actos comunicativos es posible autoevidenciar en el mundo de la vida ${ }^{2}$ cómo las tradiciones culturales hacen una conexión posible con los sistemas de la acción.

El sociólogo alemán Niklas Luhmann, basado en la teoría social desarrollada por Parsons, argumenta el vacío de las teorías sociales por limitar el alcance explicativo frente a los conceptos de diferenciación y evolución dentro de los modelos teóricos de

${ }^{2}$ Responde al ámbito de la subjetividad en el plano cotidiano, un espacio considerado previo a todo conocimiento científico. El plano donde el sujeto interactúa con el mundo desinteresadamente (Husserl, 1991). 
la sociedad, al analizar la acción y la elección desde una perspectiva unidimensional, que lo lleva a proponer una teoría de poder basada en la comunicación como marco de referencia.

El intento de formular una teoría general de la comunicación simbólicamente generalizada y de unirla con el concepto de diferenciación social tanto como con las declaraciones sobre los mecanismos y fases de la evolución sociocultural, está dirigido a llenar este vacío. (1995, p. 9)

Esta pretensión coincide con los planteamientos de Habermas al suponer que los sistemas sociales se forman a través de la comunicación. Sin embargo, Luhmann, al seguir una tradición parsoniana, no entrelaza las estructuras lingüísticas de la sociedad con las del individuo y le quita reconocimiento al conocimiento generado intersubjetivamente.

Para él, la necesidad de selecciones convenidas es la que lleva a la formación de sistemas, posibilitados por la evolución y la complejización que esta supone. La comunicación es, entonces, solo posible por medio de la capacidad selectiva de entender un mensaje; capacidad que para Luhmann resulta contingente, puesto que la selectividad en respuesta a un mensaje puede suponer rechazo o aceptación. Esta situación es la que genera conflicto. "Potencialmente, todos los sistemas sociales son conflictos; lo único que pasa es que el grado en que se rechaza el conflicto potencial varía de acuerdo al grado de diferenciación del sistema y de acuerdo con la evolución social” (1995, p. 9)

En consecuencia, y según Luhmann, las sociedades menos complejas realizan las funciones de selección por medio de construcciones de la realidad basadas en la experiencia personal, elemental, como procesos básicos de comunicación, mientras que las sociedades avanzadas generan una necesidad de diferenciación funcional entre los códigos del lenguaje y los medios de comunicación simbólicamente generalizados. Los medios de comunicación, entonces, desarrollan códigos simbólicamente generalizados, fuera del lenguaje, que orientan la acción social. Esto posibilita la creación de una explicación teórica que da seguimiento a la propuesta de Parsons frente a las expectativas y sanciones de la interacción (1960, p. 29) de cómo el poder puede funcionar como un medio de comunicación que ordena las situaciones en posibilidades de selección. Esta selectividad supone un ego que se ve afectado por las decisiones tomadas por un alter poderoso.

De acuerdo con esto, una suposición fundamental de todo poder es que la inseguridad existe en relación con la situación del alter que tiene poder. Por las razones que sean, alter tiene a su disposición más de una alternativa. Puede producir y quitar inseguridad en su compañero cuando ejerce su elección. (Luhmann, 1995, p. 13) 
En consecuencia, la función de un medio de comunicación consiste en transmitir complejidad reducida, de la selección realizada previamente por un alter frente a las posibilidades de selección de un ego.

La teoría de un medio de comunicación simbólicamente generalizado rechaza el carácter intersubjetivo en la construcción de sistemas sociales en el mundo moderno, pues asume que los sistemas son los que generan las voluntades, viendo la construcción del poder desde un plano objetivo, tomando, pues, a la sociedad como fundamento del poder por medio de la teoría de sistemas:

Ilustración, materialismo marxista, historicismo, weberianismo son, entonces, en cuanto humanismos, variantes modernas de una filosofía y de una ética social arcaicas: a ellas Luhmann contrapone el antihumanismo áspero de su "Ilustración sociológica” inspirada en la teoría sistémica, en el funcionalismo de Parsons y más en general en las teorías anglosajonas de la conducta colectiva, en la cibernética, en la teoría de juegos, en la sociología de la organización. (Zolo, 1986, p. 116)

Habermas, por su parte, rescata al sujeto, y le reclama un papel protagónico en los procesos de evolución social, procesos que están atravesados por el conocimiento generado intersubjetivamente.

Habermas retoma ese problema en el marco de una teoría crítica, es decir, trata de comprender teóricamente a la sociedad capitalista avanzada con la intención práctica de transformarla, sin perder de vista su humanización. Esta intención práctica es eminentemente crítica, porque pretende transformar, conservándola y liberándola de todas las manifestaciones ideológicas, la antigua pretensión filosófica de una verdadera racionalidad. Para Habermas, las expresiones ideológicas más importantes son el idealismo, casi en las formas más sutiles, y el positivismo de las ciencias, también en todas sus manifestaciones. El representante actual más importante de este positivismo es Niklas Luhmann, con su teoría de sistemas de la sociedad (Herrero, 1986, p. 11).

La teoría de la acción parsoniana acaba relegada a una teoría sistémica, que prescinde del ámbito intersubjetivo de la sociedad y de la acción social. Al centrar su teoría en lo sistémico, limita la comprensión de la construcción comunicacional intersubjetiva, que da cuenta del conjunto de relaciones en el mundo cotidiano. Reconoce la tensión dicotómica de la sociedad, pero, finalmente, centra todos sus esfuerzos en un desarrollo unidimensional, que constituye una teoría centrada en la razón instrumental. Al limitarse a una aplicación sistémica, Parsons y Luhmann hacen una teoría de lo objetual sin poder dar cuenta de su construcción interna por la interrelación social. Sin embargo, sientan las bases para la construcción de nuevos planteamientos teóricos desde una concepción holística de la sociedad, por lo que se tomarán bases teóricas de ambos desde una 
reconstrucción o reinterpretación de la teoría de sistemas que reclama el protagonismo de los individuos en el modelo social.

\section{Evolución social comunicacional}

Estos importantes fundamentos dialogan con la visión de la evolución social planteada por Habermas (1976) en La reconstrucción del materialismo histórico, donde apela a una teoría basada en el obrar comunicativo, que responde a una visión de la evolución social. La base para reconstruir el materialismo histórico es una recomposición de ella, en busca de expandir sus alcances analíticos, descriptivos y finalmente demostrativos de su intención inicial. De entrada, se resalta el papel comunicacional dentro del planteamiento evolucionista de la sociedad, donde el pensamiento objetivante del saber técnico, propio de la acción instrumental, se modifica por el aprendizaje generado a través del obrar comunicativo, del saber práctico, en nuevas relaciones de producción. En otras palabras, la técnica en los procesos de evolución social, por el aumento de complejidad, se modifica a través del aprendizaje generado por la comunicación en las relaciones de producción. El proceso de cambio de las estructuras normativas depende de desafíos evolutivos por las dinámicas de las estructuras del sistema y, además, el aprendizaje que se genera en los procesos internos. No es solo objetivación instrumental, sino también relaciones sociales racionales, entendiendo el proceso tanto desde las fuerzas de producción y las relaciones de producción como del conocimiento práctico-moral en las relaciones que se generan internamente.

La racionalización de la acción no repercute solo en las fuerzas de producción, sino que también tiene efecto trascendental sobre las estructuras normativas. De esta manera, la acción estratégica se va institucionalizando por medio de normas de validez que se imponen por medio de la valoración intersubjetiva. Estas normas intersubjetivas guían la acción comunicativa (Habermas, 1976, p. 33). La teoría de la evolución social se basa en modelos sociológicos y antropológicos para dar cuenta de este proceso, planteando la importancia de ambas - sociología y antropología - como las áreas de las ciencias sociales que no han perdido la referencia a la acción, siendo las únicas que hoy día pueden dar cuenta de la totalidad de la acción del sujeto (Habermas, 1981a, p. 18).

El desarrollo de la teoría de la evolución social se da mediante un proceso de racionalización del saber en la medida en que incrementa la complejidad de las sociedades. Se toma como punto de partida el planteamiento que sostiene el materialismo histórico, en relación con lo que es considerado propiamente del ser humano. Para Marx, el concepto del trabajo social caracteriza la forma de reproducción de la vida propiamente humana; sin embargo, Habermas demuestra, por medio de la antropología reciente, que el trabajo social precede a los seres humanos. El estudio contemporáneo del proceso de hominización muestra que el trabajo social tiene existencia desde muy abajo en la 
escala evolutiva. Los homínidos son los primeros seres en distinguirse por el trabajo social como una forma de organización económica. Es en ellos que se da el primer modelo de producción basado en una caza cooperativa, sostenida bajo una división social del trabajo. Los machos conformaban hordas cazadoras en las cuales debía haber un nivel básico de comunicación que permitiera una acción conjunta, de esta manera existiendo no un lenguaje como tal, pero sí un protolenguaje constituido por señas y gestos. En esta estructura, se ven estrategias de recolección y distribución que permiten la integración de un trabajo con carácter social y la formación de jerarquías y estatus, aunque son aún estructuras sociales equivalenciales que reconocen el trabajo colectivo como posibilidad de reproducción de la vida comunitaria, no individual. Debido a sus labores de casería, la estructura familiar no incorporó el rol de padre dentro de ella. No se permitía el incesto entre madre-hijo/a, ni hermano/a-hermana/o, aunque sin existir esta limitación entre padre-hija. Este problema llevó a una adecuación en el modo de producción que permitiera una familiarización del hombre en una estructura exogámica, bajo un sistema de normas que presuponen lenguaje, y así imponer el tabú del incesto.

Enrique Dussel hace una descripción normativa del anterior proceso a través del consenso intersubjetivo, solo posible por medio del lenguaje:

Quizá, para que fuera posible el intercambio, debió nacer la primera institución social presente en todas las culturas paleolíticas del Planeta: el tabú del incesto, ya supuesta la prohibición del asesinato dentro del clan o el canibalismo. Estas restricciones tenían toda la estructura de las futuras "instituciones políticas": necesidad de disciplinar el instinto (Trieb en alemán, la pulsión freudiana), postergar el deseo (sexual del acceso al hijo o a la hija, que posteriormente será en la agricultura la prohibición de comer la semilla para ser plantada o el animal reproductor del rebaño), admitir un cierto sufrimiento para postergar mayores dolores y la misma muerte; obligación de cumplir con la regla consensual (los padres no acceden sexualmente a los hijos, reservados sagradamente para otras familias del clan); imposición de castigos en el caso de no cumplimiento; celebración de ritos de reparación como posibilidad de ser nuevamente integrados en el consenso comunitario [...] Los sistemas sociales, prácticos, de reproducción de la vida exigían igualmente consensualidad -acuerdo comunitario aceptado mutuamente, como hemos indicado a manera de ejemplo, por el tabú del incesto, entre otras obligaciones-, que el lenguaje condiciona y permite. (2007a, p. 17)

De esta manera, se ve una primera etapa en la evolución social bajo una reconstrucción del planteamiento marxista, donde el trabajo precede a un desarrollo lingüístico, que da las bases para generar un sistema de roles que acogen su carácter verdaderamente humano en una organización social centrada en un modelo familiar. El desarrollo de normas en este proceso precisa de la validez intersubjetiva, comunicacional, que de 
ninguna manera pueden remitirse solo a la acción instrumental y estratégica. El ser necesitante es, antes que nada, ser social, y solo por medio de procesos comunicativos genera su relación con el satisfactor de necesidades sociales.

El concepto de modo de producción, dentro del marxismo, es la clave para entender la sucesión de etapas, históricamente organizadas, por medio de las cuales se generan procesos de evolución social. El modo de producción se da mediante la dialéctica entre medios de producción y modos de producción. La primera da cuenta de la capacidad posible dentro de los procesos naturales, mientras la segunda responde a las instituciones sociales que articulan la fuerza de trabajo con los medios de producción. El materialismo histórico ortodoxo supone un crecimiento de los medios de producción que da una sucesión jerárquica, ordenada, de ellos. El modo de producción de la comunidad primitiva, la producción antigua, el esclavismo, el feudalismo, el capitalismo, el socialismo y, como última instancia utópica, el comunismo.

El modo de producción de la vida material condiciona el proceso de vida social, político y espiritual en general. No es la consciencia de los hombres la que determina al ser, sino, por el contrario, el ser social es lo que determina su consciencia. En cierta fase de su desarrollo, las fuerzas productivas materiales de la sociedad entran en contradicción con las relaciones de producción existentes, o bien, lo que no es más que la expresión jurídica de esto, con las relaciones de propiedad, en el seno de las cuales se han desenvuelto hasta entonces. De formas de desarrollo de las fuerzas productivas, estas relaciones se convierten en trabas suyas. Y se abre así una época de revolución social. Al cambiar la base económica, se transforma más o menos rápidamente toda la superestructura inmensa (Marx, 1859, p. 7).

Habermas critica este supuesto, reclamando el protagonismo de las sociedades en la evolución, no en un seguimiento unilineal e interrumpido por la visión historicista, sino más bien por una interpretación lógica de los procesos históricos:

Los muchos caminos pueden conducir al mismo nivel de desarrollo; los desarrollos unilineares son tanto más inverosímiles cuanto más numerosas son las unidades evolutivas. Además, tampoco existe garantía ninguna de desarrollos ininterrumpidos. Que una sociedad se estanque improductivamente es un cierto grado de desarrollo o que resuelva sus problemas sistemáticos por medio del desarrollo de estructuras nuevas es algo que depende de coyunturas accidentales. [...] No son los procesos evolutivos los irreversibles, sino las secuencias estructurales por las que ha de atravesar una sociedad cuando y en la medida en que entra en evolución (las cursivas son mías). (Habermas, 1976, p. 142)

Estas bases críticas del materialismo histórico permiten abonar el terreno de una teoría evolucionista, que analiza el desarrollo social, no solo desde la evolución de las 
fuerzas productivas, sino de un aumento en la complejidad que marca los límites de la relación del hombre con la naturaleza.

La complejidad como elemento fundamental del desarrollo social sienta los cimientos sobre los que se edifica una concepción de lo político a través del lenguaje. A medida que incrementa la complejidad social, incrementan problemáticas sistémicas por resolver que requieren un desarrollo técnico en respuesta. El aumento en la complejidad, como bien lo desarrolló Marx, emana de la organización de las fuerzas productivas, del desarrollo del mercado y de la división social del trabajo. Pero la complejidad no puede analizarse en su totalidad sin tener en cuenta las relaciones que se construyen en las dinámicas de producción, pues la organización de las fuerzas de trabajo, el desarrollo del mercado y la división social del trabajo, por sí mismas, no dan cuenta de la expansión de las fuerzas productivas ni generan una explicación suficiente ante la rebelión de los pueblos.

La historia de la técnica ofrece un modelo de desarrollo complementario, mediante el cual se da una evolución en las imágenes del mundo de la vida. El incremento de complejidad y de problemáticas nuevas, según el desarrollo social e instrumental, forma estructuras complejas en respuesta a resolver las problemáticas como procesos de racionalización. Este proceso supone un desarrollo en las capacidades de aprendizaje que intersubjetivamente se incorporan en un sistema de integración social, existiendo, pues, una separación en la acción racional humana.

Según Habermas, el mundo mítico-arcaico no llega a una separación entre sociedad, naturaleza y cultura, pues no hay un desarrollo de las fuerzas de producción que permita controlar las fuerzas de la naturaleza, de modo que, racionalmente, recurre a imágenes mitológicas en respuesta a las problemáticas que suponen sus imágenes del mundo. A medida que incrementa la complejidad y el aprendizaje, se estructura una separación cada vez más clara entre sociedad, naturaleza y cultura, que permite poner un dique fáctico a la naturaleza.

Los procesos de aprendizaje intersubjetivo que suponen el incremento de la complejidad son los detonantes que permiten esta separación, la cual se desarrolla en la medida en que existe una racionalización de las ciencias que confluye en una especialización disciplinaria en desarrollo a las bases evolutivas. Esto presume un proceso de racionalización del saber a los niveles de complejidad histórica que se desarrollan dentro de las sociedades, donde la propia complejidad humana encuentra solución en la sistematización. La evolución y especialización del conocimiento da cuenta de este proceso:

En un principio la filosofía respondía a una canalización general del conocimiento, todas las disciplinas se resumían en ella. Al surgir altos niveles de complejidad y por tanto conocimiento técnico, las ciencias naturales desplazan a la filosofía en estos campos y posteriormente las ciencias sociales limitan el campo de estudio de la filosofía al conocimiento de moralidad y logos. (Habermas, 1981a, p. 19) 
La teoría de la evolución social toma las bases del marxismo en el materialismo histórico y lo complementa con una teoría de evolución comunicacional (teoría de la acción comunicativa), considerando que el materialismo histórico marcó una vía analítica acertada, pero que no previó o pasó por alto el papel que tiene la construcción de aprendizaje intersubjetivo en las respuestas racionales de las sociedades a las problemáticas que supone su nivel de desarrollo en las fuerzas productivas. Habermas se considera marxista, pero abre un campo interpretativo no muy explorado por el marxismo, debido a una predominante corriente de interpretación positivista y economicista de la teoría marxiana, sobre todo de un "marxismo darwinista", que plantea una evolución inmanente e inamovible por el desarrollo y la expansión de los medios de producción y sus tensiones con la fuerza de trabajo y le adjudica a la razón instrumental un carácter omnímodo. Esta interpretación del marxismo, que vincula la ideología propia del socialismo real, no solo no puede dar cuenta del desarrollo cultural, sino que lo interpreta como un simple reflejo de las dinámicas que surgen en el ámbito económico. En este sentido, se humanizan los procesos de creación normativa de las sociedades por medio de la evolución cognitiva, en el desarrollo de la técnica por medio de la interacción comunicacional y, por tanto, un desarrollo en consensos intersubjetivos que responden de manera racional -instrumental y comunicativa- por medio de imágenes del mundo. Este proceso se genera por medio del nivel de desarrollo de las fuerzas productivas y del nivel de complejidad social, complejidad que genera nuevos sistemas especializados y centrados en producir respuestas a complejidades específicas.

Debemos alertar el carácter ideológico de la separación que se establece entre sociedad mítica/arcaica y sociedad moderna, pues parte de una concepción iluminista y eurocéntrica que busca resaltar un determinado sentido racional-subjetivo como forma de organización de la totalidad. Base que hereda Habermas en su comprensión de la "modernidad", imperante en la filosofía occidental, que socava comprensiones cosmológicas no occidentales, como los mitos amerindios, al establecer una falsa separación "absoluta" entre hombre y naturaleza, en vez de una readecuación de interdependencia que, precisamente al considerar que existe tal separación, mercantiliza la naturaleza en valor de cambio, siendo subsumida por las lógicas del capital, en la espiral entrópica que supone el incremento de la tasa de ganancia que genera escasez y amenaza la reproducción de la vida humana.

\section{Genealogía del concepto de lo político}

La teoría de sistemas considera a la sociedad como una red de subsistemas autónomos, cada uno encapsulado conforme al otro. En este sentido, la sociedad adquiere un carácter autopoiético, ${ }^{3}$ autoorientado, donde se pierde la preeminencia de la

\footnotetext{
${ }^{3}$ Neologismo con que se denomina el sistema que puede mantenerse y reproducirse por sí mismo.
} 
comprensión jerárquica de la sociedad centrada en el Estado, ${ }^{4}$ pues cada disciplina adquiere sus propios códigos y su propia semántica, tras lo cual se debilitan los canales de comunicación intersistémica.

Es mediante la teoría de sistemas que se introduce la problematización del concepto de lo político como el sistema que debe lograr la articulación de los subsistemas autistas y cerrados autorreferencialmente. Surge, entonces, la incapacidad de explicar cómo, a pesar de la autonomía de los diversos sistemas, puede esperarse, mediante el sistema político, su mutua cohesión.

Para Luhmann, el consenso es una utopía, inalcanzable e ilusoria, pues, según él, la legitimidad deviene los procedimientos instrumentales, por lo que resulta obsoleta la noción clásica de democracia.

\begin{abstract}
Luhmann afirma que en las sociedades industriales modernas el sistema político está en grado de potenciar en tal medida su capacidad de elaborar informaciones y su indiferencia respecto de los demás sistemas sociales, que no requieren más del “consenso" de los sujetos políticos, si por consenso se entiende la adhesión atenta y motivada. El sistema políticoadministrativo dispone de instrumentos de integración y de control que autolegitiman los procesos de decisión, prescindiendo ampliamente de un imput de motivaciones, de valores y de intereses. (Zolo, 1986, p. 180)
\end{abstract}

Entendemos, por tanto, que para Luhmann la participación y el consenso son propios de un modelo político arcaico, pues considera que las sociedades modernas se rigen a través de la reducción de complejidad en la transmisión de decisiones generadas a través de las lógicas sistémicas de las sociedades modernas.

Sin embargo, estos planteamientos realistas utilizan conceptos de poder que resultan inadecuados para ver la constitución del poder respecto de un Estado de derecho, pues pasan por alto el vínculo que se da entre el derecho y el poder político. Este déficit se oculta bajo el legado teórico de Jon Elster, quien rehabilita el concepto de política deliberativa. Elster, por medio de la teoría de elección racional, analiza las posibilidades electivas y las preferencias como algo dado y cambiante según el proceso político, el cual es resultado de una construcción de la opinión y la voluntad, lo que, en términos de Elster, se denomina formación autónoma de preferencias. Si bien este planteamiento abre un espectro interpretativo desde la toma de decisiones por medio de la voluntad, se centra en el supuesto de que la motivación de la acción social se limita a una utilidad individualista.

\footnotetext{
${ }^{4}$ Se desarticula la comprensión hobbesiana del poder estructurado en el Leviatán, en el Estado, por su incapacidad de articular los diversos sistemas y subsistemas, en especial el económico. Lo que en palabras de Zygmunt Bauman sería la transición de estructuras sólidas a estructuras líquidas.
} 
La capacidad de explicación sociológica resulta limitada y gran parte de la literatura sobre elección racional adquiere una tendencia universalmente oportunista, lo que le quita contacto con el mundo real, dejando por fuera el conocimiento intersubjetivamente constituido. Elster se había movido en torno a las anteriores críticas para

ampliar con ligaduras de ética social y razones morales la base de la decisión en los casos de la acción social y a describir el proceso democrático como un mecanismo que contribuye a cambiar preferencias mediante discusiones públicas. Pero lo que sobre todo le interesa son los aspectos de procedimiento de tal formación racional de la voluntad. (Habermas, 1998, p. 416)

A partir de ahí, Elster introduce un ulterior tipo de acción, la acción regulada normativamente. Por consiguiente, Elster replica que debe suponerse en general un reconocimiento intersubjetivo de las normas. Sin embargo, este nuevo tipo de acción sigue respondiendo a premisas empiristas, por lo que, o bien despoja a las normas morales de su carácter obligatorio, o bien las incluye dentro de las normas de comportamiento obligatorio, pero desde un sentido deontológico, alejadas de su carácter racional. En ese sentido, se excluyen normativa y racionalidad y, de esta manera, el acuerdo racional queda relegado a la negociación.

Pero mientras la normativa y la racionalidad se excluyan de esta forma, las coordinaciones de la acción racionalmente motivadas solo pueden cobrar la forma de un convenio entre actores que actúan estratégicamente. Acuerdo racional viene a ser sinónimo de bargaining, de negociaciones de compromisos. Y, por cierto, con tales negociaciones, que exigen la disponibilidad a la cooperación por parte de actores orientados a su propio éxito, las normas se asocian en forma de restricciones empíricas, o de autoligaduras, que los propios sujetos irracionalmente se imponen. A este propósito, Elster desarrolla un paralelogramo de fuerzas que explica los procesos de negociación regulados normativamente como una cooperación entre expectativas racionales de éxito y normas sociales que rigen, por así decir, a las espaldas y sirven de trasfondo y marco. Pero esta forma de introducir los motivos normativos de la acción se revela como insuficiente si de lo que se trata es de explicar cómo la formación política de la voluntad puede cambiar de forma racional las preferencias de los implicados y cómo pueden abrirse de forma racional nuevas opciones (Habermas, 1998, p. 417).

La formación racional de la voluntad política debe buscarse en el plano social de deliberación y toma de resoluciones, y no a nivel individual, generando, pues, una concepción de política deliberativa. Se habla, entonces, de un poder generado comunicativamente, que se adquiere bajo la interacción de las esferas público-políticas.

Volviendo al planteamiento del carácter autopoiético de la sociedad desde la teoría de sistemas, la política también se ha aislado, cerrado sobre sí misma con sus propios 
códigos y su propio lenguaje. Los sistemas han dejado, cada vez con mayor distancia, de compartir un lenguaje común que permita comunicación e interacción entre ellos, poco a poco desdibujando el lenguaje común y corriente. Luhmann reconoce el proceso de autopoiesis semántica.

Toda ciencia depende de conceptos que determinan qué se puede diferenciar de qué, qué se puede designar, observar, escribir, y quizá, explicar. Esto no significa de ninguna manera que todo lenguaje de la ciencia consista exclusivamente en conceptos; pero sí que la ciencia se distingue de la comunicación social cotidiana solo en cuanto que utiliza conceptos y coordina su uso en su propio sentido (teórico). (1996, p. 94)

Aunque sin identificar en la autopoiesis la incapacidad de comunicación y articulación de los sistemas sociales, lo cual impide al propio sistema político responder a las demandas y dinámicas sociales.

Así es como la integración social no puede llegar solo mediante el poder político Estadocéntrico, sino mediante un lenguaje ordinario del cual se hace uso en las redes periféricas de comunicación, que constituyen el espacio público-político. Los suministros más importantes de la opinión y la voluntad hacia la política provienen de contextos informales de comunicación del espacio público del ciudadano. El lenguaje común y corriente permite que exista una comunicación en el ámbito de la opinión pública, esfera que está arraigada en el mundo de la vida, emancipado del carácter autopoiético de la sociedad en la especialización semántica de los sistemas. En este sentido, entendemos que la política está centrada en la esfera pública, no en los partidos políticos, y el espacio público-político es concebido como la caja de resonancia de los problemas propios del sistema político.

Se define, entonces, la esfera o espacio de la opinión pública como de sociedad civil, para mostrar las barreras de poder dentro de la opinión pública, que representa el centro de la política. Se entiende, pues, la esfera de la opinión pública

\footnotetext{
como una red para la comunicación de contenidos y tomas de postura, es decir, de opiniones, y en él los flujos de comunicación quedan filtrados y sintetizados de tal suerte que se condensan en opiniones públicas agavilladas en torno a temas específicos. Al igual que el mundo de la vida en su totalidad, también el espacio de la opinión pública se reproduce a través de la acción comunicativa, para la que basta con dominar un lenguaje natural; y se ajuste a la inteligibilidad general de la práctica comunicativa cotidiana (las cursivas son mías). (Habermas, 1998, p. 440)
}

Esto responde a un espacio social que es generado comunicativamente, donde la sociedad civil es la única capaz de producir una serie de asociaciones de los discursos que pueden llevar, realmente, a la solución de problemas centrados en el interés general. 
Bajo estos conceptos, se entiende que el núcleo de la política es la esfera pública o la opinión pública, la cual está enraizada en el mundo de la vida y responde como sensor ante los problemas políticos de la sociedad compleja, y la sociedad civil responde a grupos medianamente organizados que pretenden dar respuesta a las problemáticas. La sociedad civil es la institucionalización de la opinión y la voluntad política. De esta manera, el sentido de lo político hace completa contraposición a la idea en que la política se genera y desenvuelve en las instituciones y en los partidos políticos. Las instituciones, pues, son aparatajes técnico-científicos, burocracias administrativas que les dan una racionalidad a los procesos de toma de decisión, pero no son las titulares de dichas decisiones.

La articulación de la esfera pública presenta una libertad de asociación y libertad de opinión que permiten un espacio para la libre intervención de procesos de formación de la opinión pública, en respuesta a temas de interés general. Pero, y como explica Hannah Arendt, en las sociedades capitalistas avanzadas de nuestro tiempo,

la esfera pública se ha esfumado; no queda espacio alguno, sea para contemplar y ser contemplado en actividad, el spectemur agendo de John Adams, sea para la discusión y la decisión, el orgullo de ser "partícipe en el gobierno", según la expresión de Jefferson; los asuntos políticos son aquellos que dicta la necesidad y que deben ser decididos por expertos, sin que estén abiertos a las opiniones ni a una decisión libre. (1988, p. 327)

La incomunicación de los distintos sistemas sociales, producto del proceso de evolución y complejización social, genera el principal impasse ante el ejercicio del poder político, identificado, como se argumentó, en la esfera de lo público. Habermas realiza un esfuerzo importante en desmenuzar las contradicciones sistémicas en el modelo de representación, pero reduce su análisis a una ética formalista (liberal, inclusive), que dista de una mirada crítica en la estructuración de hegemonías elitistas que articulan, aún hoy, la correlación de fuerzas desde una noción clásica de clases, la cual puede resultar ambigua, pero imprescindible para comprender las contradicciones sociales.

\section{Consideraciones finales: rehabilitación de lo local e institucionalización de lo común}

Diversos teóricos de la democracia pluralista han defendido la representatividad por medio de la elección racional como espejo de la voluntad propia de la sociedad civil. Lo que el sociólogo norteamericano Seymour Lipset (1959) denominó "la lucha de clases democrática”, argumentando la existencia de todos los arreglos y las garantías sociales bajo el esquema representativo. $\mathrm{Al}$ respecto, comenta Claus Offe: 
La lógica que subyace a este análisis se puede sintetizar así: "Si la gente quisiera en realidad que las cosas fueran diferentes, elegiría simplemente a otra persona para que la gobernara. El hecho de que no lo haga es una prueba congruente de que está satisfecha con el orden político-social existente”. De este modo, nos enfrentamos con una posición que es como el reverso de la doctrina leninista: la democracia no está vinculada al capitalismo sino el capitalismo a la democracia. Ambas perspectivas niegan importantes tensiones e incompatibilidades entre la democracia de masas y la economía de mercado. (1982, p. 10)

Estas argumentaciones se sostienen sobre el supuesto de una simetría en materia de derechos, incapaces de analizar las relaciones de poder y dominación que se han estructurado por fuera de los espacios concebidos como democráticos. Las relaciones son más complejas y presentan profundas contradicciones de base entre las condiciones del mercado y las garantías de un ejercicio de poder democrático.

La democracia representativa enfrenta una crisis global por el distanciamiento entre representantes y representados, lo cual genera un vacío político debido a la incapacidad real de los funcionarios públicos en responder a las necesidades y demandas propias del mundo de la vida, agravada por las dinámicas que se producen en el plano global, que llevan el ejercicio de poder por fuera de los espacios democráticamente constituidos.

Hannah Arendt (1988) indica con potencia varias de las contradicciones que constituyen las crisis de las Republicas, vinculadas esencialmente a las modernas nociones de democracia, al suponer, erróneamente, que el fundamento esencial en la articulación gubernamental está centrado en dar respuesta al bienestar material de la población, desplazando la actividad política por la gestión administrativa y técnica a través de la representación. Lo que deviene la usurpación de la titularidad del poder de los muchos por los pocos.

El gobierno representativo se ha convertido en la práctica en gobierno oligárquico, aunque no en el sentido clásico de gobierno de los pocos en su propio interés: lo que ahora llamamos democracia es una forma de gobierno donde los pocos gobiernan en interés de la mayoría o, al menos, así se supone. El gobierno es democrático porque sus objetivos principales son el bienestar popular y la felicidad privada: pero puede llamársele oligárquico en el sentido de que la felicidad pública y la libertad pública se han convertido de nuevo en el privilegio de unos pocos. (p. 372)

Muy en la línea de lo que Rousseau (1762) ya indicaba en El contrato social, cuando afirmaba que "el pueblo inglés piensa que es libre y se engaña: lo es solamente durante la elección de los miembros del Parlamento”, agregando que el uso que ejerce el ciudadano de su libertad es tan reprobable que merece perderla para volver a ser esclavo (p. 260). 
$\mathrm{Al}$ igual que Hannah Arendt, Jacques Rancière (2000) ve en la democracia un proceso que exige del ciudadano una actitud de actividad permanente en contra de los monopolios generados por las oligarquías y las burocracias institucionales. Dichos monopolios encuentran su fundamento en la representación, que lejos de ser una forma de expresión y decisión popular, genera lo que Rancière denomina el consentimiento demandado por un poder superior (p. 78). En un modelo representativo, la titularidad del poder queda al servicio de las burocracias institucionales constituidas por una connivencia entre las élites políticas y económicas, que domestican al ciudadano a asumir una actitud dócil y pasiva, alejado de su zóon politikon, como un apacible consumidor de una democracia de mercado.

La política, en ese sentido, responde, con mayor evidencia, a intereses externos de los que devienen propiamente la ciudadanía en su noción de lo común. La raíz de la democracia se fija sobre la capacidad de conservar la titularidad del poder, es decir, no solo la capacidad por parte de la ciudadanía en poner límites a quien administra, sino ser la gestora de sus propias voluntades y de los procesos de institucionalización de estas.

Desde una concepción habermasiana de democracia, su fundamento reside en la articulación del sistema político-administrativo encargado de la toma de decisiones y la sociedad civil. De la misma forma en que reclama el imprescindible papel de la doble dimensión en la teoría social, supone que la democracia debe basarse en la articulación del ámbito sistémico reflejado en las instituciones y la voluntad de las dinámicas propias del mundo de la vida, expresadas por la voluntad de la sociedad civil medianamente organizada. En ese sentido, la toma de decisiones que se genere en las instituciones debe ser fundamentada y justificada, constantemente, por la sociedad civil a través de la esfera pública.

Para Habermas, la capacidad de construir consenso está determinada por la participación simétrica de los afectados, en el espacio público-político, a través de argumentos racionales. Pensar los procesos de deliberación en condiciones de igualdad evade la comprensión de las desigualdades presentes en la participación:

En la medida en que el hecho de poner las desigualdades sociales en paréntesis durante la deliberación significa proceder como si ellas no existiesen cuando de hecho sí existen, este hecho no proporciona una paridad en la participación. Al contrario, un puesto entre paréntesis normalmente ofrece ventajas para los grupos dominantes en la sociedad y desventajas para los subordinados. (Fraser, 1999, p. 16)

También presupone, muy en la línea de los factores de comunicación de Roman Jakobson (1958), que los significados de los mensajes son unívocos tanto para el emisor como el receptor, impregnan de totalidad los significados presentes en los procesos 
comunicacionales y abren espacio al establecimiento de consensos simbólicos desde los significantes hegemónicos.

Se entiende, desde el supuesto habermasiano, una ambivalencia en la comunicación que se expresa entre el unívoco y el equívoco. El unívoco genera un pensamiento dogmático, al entender un determinado significado como incuestionable; el equívoco, por su parte, desemboca en un pensamiento escéptico, que descarta el significado al considerarlo propiamente inválido. En ambos casos, se crea una lectura acrítica y totalizante, al olvidar la polisemia presente en los diversos significantes, lo cuales pueden existir tanto en las codificaciones y decodificaciones de mensajes en procesos comunicativos como en los significados de los conceptos centrales que estructuran los modelos de organización social modernos, como democracia, poder o representación.

Habermas, nuevamente, se limita dentro de una ética formalista. No se trata de tomar la deliberación como un terreno ya alcanzado, sino uno que debe ser labrado y constantemente reinventado, y desarrollar prácticas plurales y paralelas a las actuales por medio de la reivindicación de los procesos locales, en su pretensión de universalidad.

Las instituciones son reacias a los cambios, pues están cooptadas por burocracias statu quistas. La historia del Estado evidencia una reconfiguración de las estructuras normativas por presiones que se han ejercido a través de grupos subalternos y que generan puntos de inflexión que han forzado reestructuraciones frente a las configuraciones sociales en general o a derechos políticos de comunidades excluidas. Usualmente, estos procesos se han caracterizado por ser convulsiones violentas en la contradicción que presenta el dinamismo del mundo de la vida, frente al inmovilismo de la razón sistémica y la disputa de intereses por actores antagónicos. Toda ruptura social supone un momento de validación y factibilidad que, necesariamente, se institucionaliza en normas. Desde el tabú del incesto, pasando por las teorías de justicia egipcias encarnadas en el mito de Osiris, hasta los marcos constitucionales de los Estados modernos. Este proceso supone un momento de consenso, pero que, y como diría Antonio Gramsci (1978), es atravesado por relaciones de dominación y violencia. En la medida en que se desfetichiza la representación, se reduce el espacio entre voluntad social e institucionalización normativa que abre espacios de transformación social que generan mayor cercanía entre la comunidad y los procesos normativos, salvaguardando la supremacía de los intereses de los muchos por sobre los privilegios de los pocos.

Se deben generar dinámicas locales de desarrollo que permitan poner puntos de resistencia a las dinámicas neocoloniales de poder. Asumir como sensor de una ética crítica la representación simbólica de aquellos que, incluso en el mundo de la vida, hacen parte de narrativas periféricas de los procesos comunicacionales, de esta manera ejerciendo una resistencia, no solo en un plano económico-político, sino desde el plano 
cultural, en busca de salvar las reivindicaciones simbólicas propias de los rituales, las rutinas y las creencias de las comunidades, propiciando un diálogo intercultural que permita construir procesos contrahegemónicos.

El interés por el cosmopolitismo y la herencia común de la humanidad ha sufrido un gran desarrollo en las últimas décadas, pero también ha generado una resistencia poderosa. En particular, la herencia común de la humanidad ha estado bajo el ataque constante de los países hegemónicos, especialmente de los Estados Unidos. Los conflictos, las resistencias, las luchas y las coaliciones que se agrupan alrededor del cosmopolitismo y de la herencia común de la humanidad muestran que lo que llamamos globalización es en realidad un conjunto de arenas de luchas transfronterizas (De Sousa Santos, 2005, p. 66).

Resulta útil, a mi entender, el análisis tanto de la democracia como la estrategia para la construcción de paz, a través procesos deliberativos, dinámicos e inacabados, pues supone asumir la complejidad y la contingencia social en las luchas por alcanzar escenarios donde lo común asuma una destacada relevancia en los procesos de conceso y disenso. Cada generación ha tenido que asumir las problemáticas propias de su tiempo, reivindicando derechos sociales específicos y esperando que las generaciones venideras se encarguen de otros distintos, propios de su tiempo. Este proceso no excluye la violencia como realidad y necesidad social ante fracturas y contradicciones sistémicas irresolubles por medios noviolentos. Cuando en una sociedad un bisnieto persiste en las reivindicaciones sociales de la época de su bisabuelo, el terreno alcanzado hacia escenarios de transformación de conflictos se reduce casi a cero, e incrementa el riesgo hacia una convulsión social violenta por tal complejidad en las contradicciones sociales que resultan cíclicas ante marcos formales y segmentados, como los que impone el sistema de representación liberal formalmente expresado en las actuales democracias representativas y de mercado.

El papel de la deliberación permite entender la construcción de paz como un proceso de aprendizaje social dialéctico, en busca de que cada generación encuentre un mejor lugar para desarrollarse que el que tuvieron sus padres, asumiendo activa y deliberativamente la profundización de sentidos de liberación en la comprensión de lo democrático, como la capacidad de lo cotidiano para crear, desde lo presente, la posibilidad de lo inusitado, tomando a la vida misma con fin último.

La distinción terminológica entre emancipación y liberación tiene aquí un valor crucial: mientras que la emancipación lucha por la libertad de la identidad: la libertad de ser quien verdaderamente [ya] eres; la liberación apunta a la libertad de la autodeterminación y autotransformación: la libertad de determinar lo que [nunca fuiste y] puedes devenir. (Negri y Hardt, 2009, p. 331) 


\section{Referencias}

Arendt, H. (1988). Sobre la revolución. Madrid: Alianza Editorial.

Averitzer, L. (2001). Democracia deliberativa: la recuperación del concepto de deliberación pública en la teoría democrática contemporánea. Metapolítica, 5(18), 50-65.

Bobbio, N. y Bovero, M. (1985). Origen y fundamentos del poder político. México: Grijalbo.

Elster, J. (1995). Psicología política. Barcelona: Gedisa.

De Sousa Santos, B. (2005). The future of the World Social Forum: The work of translation. Development, 48(2), 15-22.

De Sousa Santos, B. (2006). La sociología de las ausencias y la sociología de las emergencias: para una ecología de saberes. En Renovar la teoría crítica y reinventar la emancipación social (pp. 13-41). Buenos Aires: Consejo Latinoamericano de Ciencias Sociales.

De Sousa Santos, B. (2016). A difícil democracia. São Paulo: Editorial Boitempo.

Durkheim, E. (1987). La división del trabajo social. Madrid: Akal.

Dussel, E. (2007a). Política de la liberación: historia mundial y crítica. Madrid: Trotta.

Dussel, E. (2007b). Filosofía de la liberación. Madrid: Trotta.

Fraser, N. (1999). Repensando la esfera pública: una contribución a la crítica de la democracia actualmente existente. Quito: Debate.

Fraser, N. (2007). Transnationalizing the public sphere: On the legitimacy and efficiency of public opinion. a Post-Westphalian World. Recuperado de http://eipcp.net/ transversal/0605/fraser/en

Fritjof, C. (1996). El punto crucial. Buenos Aires: Estaciones.

Galtung, J. (1996). Peace by peaceful means: Peace and conflict, development and civilization. Oslo, Norway: International Peace Research Institute.

Gramsci, A. (1978). Concepção dialética da história. Río de Janeiro: Civilização Brasileira.

Habermas, J. (1976). La reconstrucción del materialismo histórico. Madrid: Taurus.

Habermas, J. (1981a). Teoría de la acción comunicativa, I: Racionalidad de la acción y racionalización social. Madrid: Taurus.

Habermas, J. (1981b). Teoría de la acción comunicativa, II: Crítica de la razón funcionalista. Madrid: Taurus. 
Habermas, J. (1998). Facticidad y validez: sobre el derecho y el estado democrático de derecho en términos de teoría del discurso. Madrid: Trotta.

Habermas, J. (2005). Concluding comments on empirical approaches to deliberative politics. Acta Política, 4o(3), 384-392.

Herrero, X. (1986). J. Habermas: su teoría crítica de la sociedad. En F. Galván Díaz (comp.), Touranie y Habermas: ensayos de teoría social. México: Universidad Autónoma Metropolitana Azcapotzaco.

Husserl, E. (1991). La crisis de las ciencias europeas y la fenomenología trascendental. Barcelona: Crítica.

Ilivitsky, M. E. (2011). La desobediencia civil: aportes desde Bobbio, Habermas y Arendt. CONfines, 7(13), 15-47.

Jakobson, R. (1959). On linguistic aspects of translation. On Translation, 3, 30-39.

Krain, M. (1998). Contemporary democracies revisited: Democracy, political violence, and event count models. Comparative Political Studies, 31(2), 139-164.

Lipset, S. (1959).

Luhmann, N. (1995). Poder. Barcelona: Anthropos.

Luhmann, N. (1996). La ciencia de la sociedad. México: Universidad Iberoamericana.

Luhmann, N. (1998). Sistemas sociales: lineamientos para una teoría general (2. ${ }^{\mathrm{a}}$ ed.). México: Anthropos.

Marx, K. (1859). Contribución a la crítica de la economía política (trad. M. Kuznetsov). Progreso.

Negri, A. (2002). O Poder Constituinte: ensaio sobre as alternativas da modernidade (trad. A. Pilatti). Río de Janeiro: DPeA Editora.

Negri, A. y Hardt, M. (2000). Empire. Cambridge: Harvard University Press.

Negri, A. y Hardt, M. (2009). Commonwealth. Cambridge: Harvard University Press.

Offe, C. (1982). Las contradicciones de la democracia capitalista. Cuadernos Políticos, $34,7-22$.

Parsons, T. (1937). La estructura de la acción social. Glencoe, IL: The Free Press.

Parsons, T. (1951). El sistema social. Glencoe, IL: The Free Press.

Parsons, T. (1960). Pattern variables visited. American Sociological Review, 25, 467-483.

Powell, G. B. (1982). Contemporary democracies: Participation, stability and violence. Cambridge: Harvard University Press. 
Rancière, J. (2000). El odio a la democracia. Buenos Aires: Amorrortu.

Rodrik, D. (2011). La paradoja de la globalización: la democracia y el futuro de la economía mundial (trad. M. D. Crispín Sanchis). Barcelona: Bosch.

Rousseau, J. (1762). El contrato social. Editora Pillares.

Weber, M. (1985). Economía y sociedad. México: Fondo de Cultura Económica.

Žižek, S. (2014). Violence: Six sideways reflections. Editorial Boitempo.

Zolo, D. (1986). Complejidad, poder, democracia. En M. Cupolo (comp.), Sistemas políticos: términos conceptuales, temas del debate italiano (pp. 161-198). México: México: Universidad Autónoma Azcapotzalco. 